Témoigner Témoigner. Entre histoire et mémoire

Getuigen Revue pluridisciplinaire de la Fondation Auschwitz

$121 \mid 2015$

Violences radicales en scène

\title{
Le paradigme indiciaire chez Ginzburg
}

\section{Louise Bacquet}

\section{OpenEdition}

\section{Journals}

Édition électronique

URL : https://journals.openedition.org/temoigner/3555

DOI : 10.4000/temoigner.3555

ISSN : 2506-6390

Éditeur :

Éditions du Centre d'études et de documentation Mémoire d'Auschwitz, Éditions Kimé

Édition imprimée

Date de publication : 1 octobre 2015

Pagination : 175

ISSN : 2031-4183

\section{Référence électronique}

Louise Bacquet, «Le paradigme indiciaire chez Ginzburg », Témoigner. Entre histoire et mémoire [En ligne], 121 | 2015, mis en ligne le 01 octobre 2016, consulté le 04 février 2022. URL : http:// journals.openedition.org/temoigner/3555; DOI : https://doi.org/10.4000/temoigner.3555

Ce document a été généré automatiquement le 4 février 2022.

Tous droits réservés 


\title{
Le paradigme indiciaire chez Ginzburg
}

\author{
Louise Bacquet
}

1 L'historien Carlo Ginzburg s'est appuyé sur une méthode attributionniste mise au point par l'artiste et politicien Giovanni Morelli entre 1874 et 1876, pour proposer une nouvelle façon de faire l'histoire et de comprendre la société. Selon Morelli, la meilleure méthode pour attribuer une toile à un peintre sans commettre d'erreur, c'est d'identifier ce qui représente sa signature en termes de détails picturaux. Par exemple, l'observation de détails non enseignés en école d'art tels que les orteils, les oreilles ou encore les ongles permettent de différencier de nombreux peintres et ainsi, par un travail de comparaison et de logique, d'identifier l'auteur d'une œuvre. On pourrait rapprocher cette démarche de ce que Roland Barthes appelle «l'effet de réel ».

2 Dans son article "Signes, Traces, Pistes - Racines d'un paradigme de l'indice", Carlo Ginzburg explique que cette façon d'analyser une œuvre sur la base "d'indices » peut être traduite dans un langage plus général et devenir un modèle épistémologique satisfaisant pour les sciences sociales et plus particulièrement l'histoire.

3 S'intéresser aux traces de l'histoire, c'est faire le pari que celles-ci révèlent des aspects ignorés du passé par une analyse historique globalisante et macroscopique, c'est vouloir comprendre des événements complexes, en attachant de l'importance et de l'attention à l'anomalie. On peut reconnaître à Edouardo Grendi la paternité de l'expression «l'exception normale » pour qualifier les observations marginales, les documents inédits et usuellement laissés de côté par les historiens, toutes ces "déviations qui impliquent la norme ", pour reprendre les propos de Ginzburg. Ainsi, ces détails auxquels les microhistoriens s'attachent éclairent des phénomènes difficiles à appréhender.

4 À titre d'exemple, dans son ouvrage intitulé «Le fromage et les vers » dans lequel il étudie la vie d'un meunier du Frioul au XVI ${ }^{\mathrm{e}}$ siècle, Carlo Ginzburg raconte comment Menocchio a été brûlé vif sur un bûcher de la Sainte Inquisition pour hérésie. Lors de l'étude des deux procès que l'Inquisition fit subir à ce meunier, Ginzburg remarque que celui-ci est nourri d'une culture littéraire surprenante du point de vue de sa position 
sociale. L'historien découvre que sa connaissance des livres et, notamment, de Boccace est façonnée par sa culture orale. À partir de là, il révèle que culture paysanne et culture savante n'étaient pas totalement opposées, contrairement à ce qui semblait jusqu'alors évident. Il considère qu'étudier la vie de Menocchio lui a finalement permis de « penser la circularité des savoirs, leur circulation entre les différentes couches de la société, (longtemps) niée ou laissée dans l'ombre.»

Il résume ici toute la finalité de cette discipline qu'il contribue à développer depuis la fin des années 1980. Au-delà d'un renouveau historiographique, cette façon de faire l'histoire à partir de détails accroît la crédibilité des historiens.

\section{BIBLIOGRAPHIE}

Carlo Ginzburg, « Signes, Traces, Pistes - Racines d'un paradigme de l'indice », Le Débat, Paris, Gallimard, 1980, $n^{\circ}$ 6, p. 3-44.

Carlo Ginzburg, Le fil et les traces. Vrai faux fictif, Paris, Verdier, 2006.

Roland Barthes, «L'effet de réel » in Le Bruissement de la langue. Essais critiques IV, Paris, Seuil, 1984, p. $167-174$.

\section{AUTEUR}

LOUISE BACQUET

IEP Paris 